\title{
Hypomorphic RAG1 Deficiency
}

National Cancer Institute

\section{Source}

National Cancer Institute. Hypomorphic RAG1 Deficiency. NCI Thesaurus. Code C126338.

A condition of decreased or absent presence or activity of $\mathrm{V}(\mathrm{D}) \mathrm{J}$ recombination-activating protein 1. Deficiency of this protein is associated with Omenn syndrome, severe combined immunodeficiency, b cell-negative, combined cellular and humoral immune defects with granulomas, and alpha/beta T-cell lymphopenia with gamma/delta T-cell expansion, severe cytomegalovirus infection, and autoimmunity. 